\title{
A COMPARATIVE EVALUATION OF COMPRESSIVE STRENGTH OF POSTERIOR RESTORATIVE MATERIALS: AN IN VITRO STUDY
}

\author{
Gurmeen Kaur $^{1}$, Chitharanjan Shetty ${ }^{1}$, Aditya Shetty ${ }^{1}$, and MITHRA HEGDE ${ }^{1}$ \\ ${ }^{1}$ AB Shetty Memorial Institute of Dental Sciences
}

February 23, 2021

\begin{abstract}
BACKGROUND AND OBJECTIVES: The 'Basic filling materials' Amalgam and glass ionomer have been well accepted for posterior restorations, but have multifarious drawbacks such as low flexural strength, surface wear, porosity of glass ionomer cements, intrinsic grey unaesthetic appearance of amalgam, its inability to bond tooth and concerns about mercury content. Hence, newer materials were introduced in the market with better biomechanical properties. The present study aimed to evaluate and compare the compressive strength of Ceramic-Reinforced Glass Ionomer cement, Zirconia-Reinforced Glass Ionomer cement, High Strength Glass Ionomer Posterior restorative material, Alkasite restorative material, and Amalgam when used as posterior restorative materials. METHODOLOGY: Fifty cylindrical specimens measuring $6 \mathrm{~mm}$ in height and $4 \mathrm{~mm}$ in diameter were fabricated using test materials. Class II cavity was prepared on fifty intact permanent human molar teeth and randomly divided into five groups based on the material to be filled with ten specimens each: Group 1- Ceramic-Reinforced Glass Ionomer cement, group 2- Zirconia-Reinforced Glass Ionomer cement group 3- High Strength Glass Ionomer Posterior restorative material group 4- Alkasite restorative material and group 5- amalgam. All the specimens were thermocycled and stored in artificial saliva for 24 hours. The specimens were subjected to compressive strength testing using Universal Testing Machine (Zwick Roell, Z020, Zwick, Ulm, Germany). Data were analyzed statistically using IMB SPSS Statistics, Version 22 (Armonk, NY: IBM Corp). RESULTS: The present study reveals a significantly high compressive strength of cylindrical specimens of Group 4, followed by Group 5, Group 3, Group 1, and least by Group 2. The highest maximum compressive load was supported by teeth restored with the material of Group 4, Group 1, Group 5, Group 2, and least by Group 3. CONCLUSION: Within the limitations of the study, alkasite restorative material showed the highest compressive strength in cylindrical and tooth specimens.
\end{abstract}

\section{Hosted file}

ijcp.pdf available at https://authorea.com/users/397467/articles/510345-a-comparativeevaluation-of-compressive-strength-of-posterior-restorative-materials-an-in-vitro-study

\section{Hosted file}

figures.pdf available at https://authorea.com/users/397467/articles/510345-a-comparativeevaluation-of-compressive-strength-of-posterior-restorative-materials-an-in-vitro-study 